\section{THE PASTEURIZATION OF MILK*}

G. S. WILSON, M.D., F.R.C.P. D.P.H.

Professor of Bacteriology as applied to Hygiene, London School of Hygiene and Tropical Medicine

It is frankly impossible, in the space allowed, to put forward the full case for compulsory pasteurization of milk or to answer the numerous objections that have been raised against it. A few years ago, owing to insufficient evidence, scientific opinion was divided on pasteurization. Since then numerous experiments have been carried out in the laboratory and in the field, the results of which show that pasteurization brings about no detectable change of any significance in the nutritive value of the milk. Objections are frequently raised to it on pseudo-scientific grounds, but the real objection in the past has been financial, and has come from the producer-retailers. Before the war farmers of this kind received both the producers' and the distributors' profit ; if they had been compelled to pasteurize their milk themselves, or to arrange for its pasteurization elsewhere, their receipts would have been slightly diminished. Now, however, when the Milk Marketing Board buys all their milk and sells it to them again at a uniform price, whether raw or pasteurized, this financial objection no longer has any weight.

In the following brief summary statements will have to be made without qualification, and without providing the evidence on which they are based. Those who are anxious for further information may be referred to a report which I made to the Ministry of Health and which has been published recently in book form. $t$

Question 1: Why is there a Milk Problem ?

Answer.-Cows' milk is a food of exceptional value for the growing child. It contains a well-balanced mixture of fat, carbohydrate, and first-class protein ; it is rich in mineral salts, especially calcium and phosphorus; and it contains important vitamins. On the other hand, it is more often infected with pathogenic bacteria and more likely to give rise to disease than any other common article of our dietary. Hence arises the double problem of how to improve the nutritional status of the young without spreading milk-borne disease, and how to abolish milk-borne disease without lowering nutritional standards.

Question 2: To What Extent is Raw Milk infected with Pathogenic Bacteria?

Answer.-About 5 to $10 \%$ of farms in this country are sending out milk containing tubercle bacilli ; about 20 to $40 \%$ Brucella abortus; and a much higher proportion mastitis streptococci, which, though not usually infective to man, may cause undesirable changes in the milk. "Accredited" milk appears to be as heavily infected with tubercle bacilli as ungraded milk; and tuberculin-tested (T.T.) milk is just as heavily infected with $B r$. abortus as ungraded milk, if not more so. Bulked milk reaching our large towns usually contains all three organisms - namely, tubercle bacilli, Br. abortus, and mastitis streptococci. Occasionally milk becomes infected with other organisms, such as scarlet fever streptococci, diphtheria bacilli, and bacilli of the typhoid, paratyphoid, food-poisoning, and dysentery groups.

Question 3 : How do Pathogenic Organisms reach the Milk ?

Answer.-Tubercle bacilli, Br. abortus, and mastitis streptococci, from the cow's udder; organisms of the typhoid, paratyphoid, food-poisoning, and dysentery groups, either from the infected fingers of those handling the milk or from water used for washing the cows' udders, cleaning the milk utensils, or watering the milk ; scarlet fever streptococci and diphtheria bacilli, from the cough-spray of the milker or from the infected udder of the cow.

Question 4: How Much Disease is Raw Milk responsible for in the Human Population?

Answer.-In England and Wales about 1,500 to 2,000 deaths a year from tuberculosis of bovine origin; 400 to 500 cases of undulant fever : occasional outbreaks of scarlet fever, septic sore throat, diphtheria, typhoid fever, paratyphoid fever, dysentery, and acute gastro-enteritis. It is known that during the years 1912 to 1937 there were at least 113 outbreaks of epidemic disease in Great Britain, affecting about 14,000

* This article is contributed by special request.-ED., B.M.J.

t The Pasteurization of Milk, by G. S. Wilson. Ëdward Arnold and Co., London. 1942. persons. During the same time about 65,000 persons in England and Wales died of tuberculosis of bovine origin, and an unascertained number, probably several thousands, suffered from undulant fever contracted through milk. If epidemic summer diarrhoea in infants under 2 years of age is included, some of the deaths during this period, which in England and Wales amounted to 190,000 , must be added to this total.

Question 5: Why do Some Practitioners Belittle or Deny the Existence of Milk-borne Tuberculosis ?

Answer.-Because their clinical training makes them think in terms of the individual rather than of the herd. They do not realize that if every practitioner saw a case only once in 5 years there would be 8,000 cases annually in England and Wales.

Question 6: How can Milk be Rendered Safe for Human Consumption?

Answer.-Tuberculosis and undulant fever could be avoided by the establishment of tuberculin-tested and abortion-free herds. Diseases of the typhoid, paratyphoid, food-poisoning, and dysentery groups might be diminished to some extent by a rigid clinical and bacteriological supervision of all those employed in handling milk, and by the provision to all farms and dairy establishments of a safe water supply. Since about $40 \%$ of the cattle in this country react to the tuberculin test. and about one in every 200 cows is excreting tubercle bacilli in its milk, the establishment of sufficient $T_{1} . T$. herds to provide liquid milk for the human population would be an enormous task. It may be pointed out that in the United States, where a campaign for the eradication of tuberculosis among cattle was started in 1917, an initial tuberculin-positive rate of $4 \%$ was reduced by 1939 to a rate of about $0.5 \%$, at a cost of $\$ 260,000,000$. In this country we should have to start with a rate ten times as high, and with herds far more closely packed together than in the States. The control of contagious abortion, which is widespread in cattle, presents an almost insuperable problem, as does that of mastitis. Control of the human personnel handling the milk is not reliable, and even if it were it would create so many administrative difficulties as to be unworkable. The only practicable method at present as to be unwork human population is supplied with milk free from pathogenic organisms is by some form of heat treatment, of which pasteurization, if carried out under proper conditions, is undoubtedly the most satisfactory.

\section{Question 7 : What is Pasteurization ?}

Answer.-Pasteurization is a loose term applied to several forms of heat treatment of milk. In this country, however only two methods of pasteurization are officially allowednamely, pasteurization by the holder method and pasteurization by the high-temperature short-time (H.T.S.T.) method. In the holder method the milk must be retained at a temperature of not less than $145^{\circ} \mathrm{F}$. and not more than $150^{\circ} \mathrm{F}$. for at least 30 minutes, and then cooled to a temperature of not higher than $55^{\circ} \mathrm{F}$. The milk must not be heated more than once. The processing plant must be provided with indicating and recording thermometers, and temperature records must be preserved for a period of not less than 1 month. In the H.T.S.T method the milk must be retained at a temperature of not method the milk must be retained at $152^{\circ} \mathrm{F}$. for at least 15 , in an apparatus that is thermostatically controlled and provided with an automatic device to divert the flow of any milk which has not been so device to divert the mow then be cooled as under the holder process. The efficiency of either method may be tested by means of the phosphatase reaction. "The enzyme phosphatase is destroyed by a time-temperature combination slightly higher than that necessary to destroy tubercle bacilli. Milk, therefore. than that necessary to destroy tuse negative can be regarded for all practical purposes as free from pathogenic organisms.

Question 8: What Effect has Pasteurization on the Properties and Nutritive Value of Milk ?

Answer.-About $5 \%$ of the lactalbumin is coagulated the coagulation time by rennin is lengthened, but the casein clot formed consists of finer particles and is of a more open texture there is a diminution of about $5 \%$ in the soluble calcium and there is a diminution of about $5 \%$ in the soluble calcium and phosphor of vitamin $C$; the flavour of the milk is somewhat altered of vitamin C; the flavour of the milacts from the raw milk, owing to the removal of volatile products from the raw milk, but in properly pasteurized milk the acquirement of a cooked flavour is practically negligible and cannot be distinguished is increased considerably. Against these positive changes may is increased considerably. Agative findings. Observations on rats, mice, calves, and children have failed to reveal any change in the biological value and digestibility of the protein, in the availability of the calcium and phosphorus, in the amount of vitamin 
A or D, or in the total energy or nutritive value of the milk for the growing animal.

\section{Question 9 : Does Pasteurization Destroy Pathogenic Organisms} in the Milk?

Answer.-The tubercle bacillus is destroyed by a temperature of $138^{\circ} \mathrm{F}$. in 30 minutes, of $145^{\circ} \mathrm{F}$. in 5 to 10 minutes, of $150^{\circ} \mathrm{F}$. in 2 to 5 minutes, and of $160^{\circ} \mathrm{F}$. in 12 seconds. It will be seen that there is an ample margin of safety in the time-temperature combination laid down .or the holder method, and a fair margin of safety in that laid down for the H.T.S.T. method of pasteurization. Other pathogenic organisms-with the exception of Staphylococcus aureus, which is not pathogenic by the mouth-are more susceptible to heat than the tubercle bacillus, so that their survival in pasteurized milk is improbable.

\section{Question 10: Is Pasteurization Antagonistic to Clean-Milk} Production?

Answer.-It is not sufficiently appreciated that the quality of the pasteurized product depends to a considerable extent on the cleanliness of the raw milk. It is therefore to the advantage of the large dairy companies practising pasteurization to obtain the highest quality of raw milk. To most farmers it is immaterial whether their milk is pasteurized or not. Their real motive for improving the cleanliness of their supply is financial. The operation of the accredited-milk scheme in this country showed that a bonus payment of 1d. a gallon for accredited milk led to an enormous increase in the number of registered suppliers, in spite of the fact that a large part of the milk so produced was being taken to London and the large towns to be pasteurized. It is sometimes objected that a farmer who has taken considerable trouble to produce clean milk will be disheartened if he finds that his milk is to be mixed with that of a lower standard of cleanliness from other farmers. Perhaps this is true, but it is an argument not against pasteurization but against the bulking of milk.

Question 11 : Is Pasteurization Antagonistic to the Eradication of Diseased Animals from Milking Herds?

Answer.-As with clean-milk production, the stimulus to eradicate disease is almost purely financial, and is unaffected by the subsequent history of the milk. This has been amply shown by the success of the Tuberculosis (Attested Herds) Scheme, in which financial support was given to the producer who was anxious to eradicate tuberculosis from his herd. It is also borne out by the experience of the United States. In 1936, for example, no less than $99.8 \%$ of raw milk and $99.2 \%$ of pasteurized milk distributed in towns of 1,000 inhabitants and over was derived from T.T. herds. The two figures are so nearly identical as to lend no colour to the view that pasteurization retards the process of disease eradication.

Question 12 : How Often is Pasteurization Inefficient ?

Answer.-The term "pasteurized" is often applied erroneously to any heat-treated milk, not solely to milk that has been heat-treated in a licensed plant by one or other of the two methods laid down by the Ministry of Health. Many of the statements that pasteurized milk has been found to contain tubercle bacilli are incorrect if the word "pasteurized" is limited, as it should be, to officially pasteurized milk. Stringent requirements are exacted under the Milk (Special'Designations) Orders of 1936 and 1938. In addition we have now a reliable test-the phosphatase test-for determining whether or not the milk has been adequately heat-treated. The proportion of inefficiently pasteurized milk is therefore much less than ten years ago. Examination of 1,439 samples of pasteurized milk taken during 1934 to 1936 in London, Manchester. Sheffield, and Liverpool failed to reveal living tubercle bacilli in a single sample, in spite of the fact that the raw supply was often infected. It is not denied that the record of small dairies may be less satisfactory than that of the larger dairies supplying our great cities, but if compulsory pasteurization was introduced more thorough supervision would be exercised over these smaller plants. Admittedly, owing to some undetected fault in the plant or to some human error, the milk may at times be inefficiently heated; but there is no more reason to condemn pasteurization on this account than there is to condemn railway transport because of the occasional failure of the signal system.

Question 13 : Does the Consumption of Raw Infected Milk in Childhood Protect against Pulmonary Tuberculosis in Adult Life ?

Answer.-Though some doctors believe this to be true, there is no reliable evidence in its support. Those who do advocate the consumption of raw infected milk fail to realize that what they are recommending is a method of indiscriminate vaccination with living tubercle bacilli in the hope that, by a process of natural selection, the survivors will be more resistant in later life to invasion by the human tubercle bacillus. Against what other disease, it may be asked, would a method of vaccination be tolerated that is known to demand at present the sacrifice of 1,500 to 2,000 lives a year?

\section{Conclusion}

Cleanliness of production is no safeguard against tuberculosis or contagious abortion in the cows; and T.T. milk is just as exposed as ungraded milk to infection from human sources. Though the ultimate ideal may be clean milk produced from disease-free herds and protected from human contamination, there is no other immediate practical solution to the problem of supplying safe milk to the public but pasteurization. Whether we like it or not, the logic of the case is inexorable.

\section{EXPERIENCES IN A MILITARY HOSPITAL IN FREE CHINA \\ BY}

\author{
H. T. LAYCOCK, M.B., F.R.C.S. \\ Surgeon, Friends' Ambulance Unit in China
}

In February and March, 1942, I had the strange experience of doing surgery in a military hospital in Kiangsi Province, in S.E. China. To reach this area it was necessary to make an overland journey of about 2,500 miles from Rangoon.

$\mathrm{K}$. is a large Chinese city, the foreign residents of which are practically limited to two small mission communities. Several widely differing dialects are spoken, so there are formidable obstacles for the linguistic amateur. The nearest battle front is several hundred miles away in N. Kiangsi. The hospital in which I lived had 100 beds, a primitive operating theatre and laboratory, but no $x$-ray department. There were a few civilian victims of a recent air raid, and the other cases were all of wounded soldiers. There was no one practising surgery when I arrived, nor was there at the military hospital of 600 beds outside the city. I was received with great cordiality by the medical staff and by the local military commander, and was invited to help myself freely to surgical material from both institutions. I was further assured that when I had finished with these there were 4 more military " hospitals" waiting for me at greater distances. I use inverted commas advisedly because it requires some imagination. to describe as hospitals some of the dumping-grounds in which many Chinese wounded soldiers develop their chronic lesions.

\section{Medical and Nursing Staff}

Our hospital was relatively good. It had been built up by the New Life Medical Movement, founded at considerable sacrifice by a group of doctors who gave up lucrative practices in the occupied areas in order to help Free China. The staff consisted of 3 doctors, of whom 2 had good qualifications and a knowledge of English. The third, alas! had neither. China has some excellent medical schools, but in others the qualifying standard is a low one, perhaps comparable to that required of a sub-assistant surgeon in India. A difference is that in China the holder is not debarred, if he can pull the necessary strings, from holding the most senior posts in hospitals. There were 7 nurses, of whom 2 were well trained, while the rest tried to make up for their amateur status by their infectious enthusiasm. There was unfortunately no system of night nurses, and from 8 p.m. until 8 a.m. the patients were at the mercy of a number of nondescript "boys," who were as likely to consign to perdition anyone who complained as to fetch help. On one occasion one of these "boys" showed a deplorable complacency in the presence of secondary haemorrhage.

\section{Types of Wounds}

The military patients came from various battle areas, especially from that around Changsha. All were more or less chronically disabled, and the majority had unhealed wounds of from 6 months to 4 years' duration. These cases of unhealed wounds fell into 3 classes. In the largest $(45 \%)$ there was a sinus, or sinuses, connected with chronic osteomyelitis and/or a foreign body. I had no $x$-ray apparatus to guide me, but found in nearly every case that exploration was justified by the results. A typical case was that of a soldier, aged 24 , wounded 3 years before. He said he had had 9 operations, 'presumably curettings, during this time. He had a completely stiff ankle associated with 3 sinuses. I explored a cavity in his tarsus and 